\title{
Restricted gene flow and genetic drift in recently fragmented populations of an endangered steppe bird
}

\author{
María Méndez ${ }^{\Uparrow}$, José L. Tella, José A. Godoy \\ Estación Biológica de Doñana (EBD-CSIC), Avda. Américo Vespucio s/n, 41092 Sevilla, Spain
}

Keywords: Chersophilus duponti Habitat

fragmentation Genetic

structure Crowding

effect Conservation

\begin{abstract}
a b s t r a c t
Identifying the genetic processes derived from habitat fragmentation is critical for the conservation of endangered species. We conducted an integrated analysis of genetic patterns in the endangered Dupont's lark (Chersophilus duponti), a circum-Mediterranean songbird threatened by the loss and fragmentation of natural steppes in recent decades. After sampling all the remaining Spanish populations and the two closest North African ones, we found that the Mediterranean Sea acts as a major barrier against gene flow and that recent habitat fragmentation is isolating Spanish populations at different spatial scales. While we found a historical signal of gene flow among Spanish regions, a coalescent model supported that the ancestral panmictic population is evolving into several different units in the absence of current gene flow, genetic drift being more intense in the smaller and more isolated populations. Moreover, small-scale spatial autocorrelation analyses showed that genetic differentiation is also acting within populations. The spatial genetic structure, significant levels of inbreeding and high relatedness within patches raise concerns on the viability of most of the extant populations. We highlight the urgency for steppe patches to be protected, expanded and reconnected, considering the genetic clusters identified here rather than the previously considered eco-geographic regions occupied by the species. Meanwhile, translocations could be considered as a complementary, faster management action to attenuate the crowding and genetic effects of population fragmentation and the extinction risk of small populations without compromising the current local adaptations, culture diversity and genetic clusters already known for the species.
\end{abstract}

\section{Introduction}

Habitat loss and fragmentation often lead to the reduction and isolation of populations, and the associated increase in genetic drift might result in subsequent losses of genetic diversity and increases in inbreeding and differentiation (Frankham et al., 2002). These genetic effects of habitat deterioration may then compromise the fitness of populations and their ability to adapt to a changing environment, thereby increasing their risk of extinction (Frankham, 2005). It thus becomes essential to gauge the genetic processes that are affecting endangered populations in order to design effective conservation strategies.

Most anthropogenic fragmentation is recent in evolutionary time scales, so investigations of its effects can be biased by time lags in the responses of species to habitat deterioration (e.g. Sumner et al., 2004; Richmond et al., 2009). These delays occur as populations establish new genetic and community-level equilibriums, and they may vary widely across species. Although small and isolated populations usually lose genetic variability more quickly than larger and continuous populations, those species with a high degree

\footnotetext{
$\Uparrow$ Corresponding author. Tel.: +34 954466700; fax: +34 954621125 . E-mail address: maritxu.mendez@gmail.com (M. Méndez).
}

of ecological specialization and restricted dispersal are more susceptible to habitat deterioration (Davies et al., 2004). On the contrary, species that live in naturally patched environments with small population sizes may experience greater inertia in their responses than species that require large continuous habitats (Richmond et al., 2009). Besides, populations occupying contiguous habitat that are in genetic equilibrium are expected to follow an isolation-by-distance (IBD) model, where the distance between populations is the overriding factor contributing to genetic differentiation (Slatkin, 1993). Habitat fragmentation can however limit gene flow and lead to the isolation of populations through the creation of an unsuitable habitat matrix that limits the connectivity among the remaining habitat patches, eventually eroding preexisting IBD patterns (Gerlach and Musolf, 2000).

Fragmentation has affected many different natural habitat types, one of them are the steppes that have been severely impacted in the last decades (Laiolo and Tella, 2006a), despite being among the most valuable and endangered habitats in Europe (Tucker and Heath, 1994). Steppes are considered as unproductive and unattractive because of its low economic profitability. Therefore, large steppe surfaces were transformed into agricultural lands in the last half of the 20th century, a process of habitat loss and fragmentation that still continues (Laiolo and Tella, 2006a). This 
large-scale process has affected a number of species highly adapted to this arid ecosystem, to the point that several of them are facing serious risks of extinction (Burfield and Van Bommel, 2004). Here, we focus on the Dupont's lark (Chersophilus duponti), a songbird restricted to natural steppe vegetation in Europe and North Africa (Cramp, 1988). The Dupont's lark is the most dramatic example among endangered steppe birds. European populations are now restricted to Spain, where habitat destruction and its conversion into agricultural land in recent decades (Laiolo and Tella, 2006a) have confined the species to scattered patches with variable sizes and degrees of isolation, embedded in an unsuitable landscape matrix (Laiolo and Tella, 2006b; Fig. 1). This process has been extensive and fast enough to drive several populations to extinction in recent years (Tella et al., 2005; Laiolo et al., 2008; Vögeli et al., 2010). Current population sizes are roughly estimated in ca. 2000 breeding pairs for Spain and 5500-10,000 for North Africa (BirdLife International, 2008). Low population numbers and negative population trends have promoted the uplisting of Dupont's lark to "Endangered" in the Spanish Red List (Garza et al., 2004) and "Near Threatened" in the IUCN Red List (BirdLife International, 2008).

Although Dupont's lark is currently the subject of several conservation research studies (Garza et al., 2005; Laiolo and Tella, 2005, 2006a,b, 2007, 2008: Laiolo et al., 2008; Seoane et al., 2006; Suárez et al., 2009; Vögeli et al., 2008, 2010, 2011a,b), genetic processes occurring within and among populations remain largely unknown. A recent phylogenetic study showed that the Spanish populations are isolated from the Moroccan ones (García et al., 2008). Moreover, the restrictive habitat selection patterns (Garza et al., 2004; Vögeli et al., 2010), low dispersal and high site fidelity (Laiolo et al., 2007; Vögeli et al., 2008) suggest that current Spanish populations could be also demographically isolated. Indeed, several lines of evidence add support for a scenario of isolated populations derived from recent habitat loss and fragmentation. First, capture-recapture studies have shown extremely low dispersal ability (200-300 m with a maximum of $20 \mathrm{~km}$; Laiolo et al., 2007; Vögeli et al., 2008, 2010). Second, studies of Dupont's lark male learned vocalizations showed that habitat patchiness increases call dissimilarities at a national scale, reducing the



Fig. 1. Distribution of the Dupont's lark (shaded grey areas), study populations (black dots) and their grouping into broad geographic areas (dashed lines); Northern Plateau (NP), Ebro Valley (EV), Iberian Mountains (IM), Southern Plateau (SP), Southern Spain (SS) and Morocco(M). Numbered circles represent the genetic clusters according to Geneland analysis results. acoustic diversity within populations and increasing the differentiation among them (Laiolo and Tella, 2006b). Besides this largescale isolation, populations also reflect problems of simplifications of repertories (cultural erosion) at a regional scale: as patch size, population size and connectivity decrease, song repertoires of local populations suffer a cultural bottleneck and decline in variety (Laiolo and Tella, 2007). Those investigations also showed that spatial autocorrelation, measured as similarities between singing individuals, occurred at short distances classes even within steppe patches (Laiolo and Tella, 2005). Third, the extinction of local populations has been positively related to their spatial isolation (Vögeli et al., 2010). Fourth, the study of parasite and pathogen burdens in Dupont's larks suggests that local populations are poorly connected, thus resembling a host-parasite system typical of oceanic islands (Vögeli et al., 2011b). Therefore, demographic, cultural and epidemiological studies indicate a high sensitivity of this species to anthropogenic habitat fragmentation that might have also affected genetic variation patterns. Our aim here is to identify the patterns of genetic differentiation, diversity and disequilibrium of Dupont's lark populations examined at several spatial scales, which could help to plan effective management actions.

\section{Materials and methods}

\subsection{Study areas, samples and genotyping}

We sampled Dupont's larks in 48 Spanish localities, exhaustively covering its whole distribution, and two populations in Morocco (Fig. 1). As Laiolo and Tella (2006a) detailed, sampled Spanish populations are situated in five well-delimited ecogeographic regions (Fig. 1) that differ greatly in topography, climate and fragmentation, showing a decreasing gradient in population numbers and an increasing gradient in fragmentation: Iberian Mountains (IM), Ebro Valley (EV), Southern Plateau (SP), Northern Plateau (NP) and Southern Spain (SS). We captured 537 Dupont's larks from 2002 to 2008 with clap nests baited with meal worms (Vögeli et al., 2007). A drop of blood was extracted from the brachial or the jugular vein and stored in pure ethanol. We also registered the UTM coordinates for each individual with a GPS. Birds were captured under permits of all competent wildlife agencies and immediately released in the same places.

The aim of the study is to describe contemporary genetic patterns of Dupont's lark populations and to investigate the impact of recent demographic history, a purpose for which highly variable nuclear autosomal markers, like microsatellites prove particularly useful (Schlotterer, 2004). We therefore extracted DNA following Gemmell and Akiyama protocol (1996) and amplified for 14 microsatellite loci specifically developed for the Dupont's lark (GenBank accession numbers HM749624-HM749643) under the same conditions as in Méndez et al. (2011). Products were pooled and analysed in an ABI 3100 Genetic Analyser (Applied Biosystems) using Genemapper v4.0 (Applied Biosystems). We did not detect in Méndez et al. (2011) genotyping errors due null alleles, allele dropout, scoring errors or typographic errors with Microcheker (Van Oosterhout et al., 2004), nor individual samples or loci disproportionally contributing to Hardy-Weinberg disequilibrium, following Morin et al. (2009). We are thus confident of the usefulness and robustness of these microsatellite markers for the purposes of this study.

\subsection{Data analysis}

\subsubsection{Population's delimitation}

We initially considered each sampled locality as a potential population except for those with very low numbers of individuals 
$(\mathrm{N}<10)$. We then investigated if neighbouring localities (closer than $20 \mathrm{~km}$, the maximum dispersion distance known for the species, see Vögeli et al., 2010) were genetically structured; if they were not, we merged them for further analyses. This resulted in 33 populations for Spain and two for Morocco.

\subsubsection{Genetic diversity}

We estimated observed and expected heterozygosities $\left(\mathrm{H}_{\mathrm{o}}\right.$ and $\mathrm{H}_{\mathrm{e}}$ ), deviations from linkage equilibrium (LD), and Hardy Weinberg Equilibrium (HWE) with GENEPOP on the web (Raymond and Rousset, 1995; Rousset, 2008) using 10,000 dememorization steps, 1000 batches and 10,000 iterations per batch. When appropriate, we applied a Bonferroni correction for multiple comparisons. We also estimated the allelic richness (AR) using the rarefaction method in FSTAT 3.9.2 (Goudet, 2001). Population inbreeding coefficient $\left(\mathrm{F}_{\mathrm{is}}\right)$ was calculated with Genetix (Belkhir et al., 1996-2004), with 10,000 permutations to assess significance.

\subsubsection{Bayesian clustering analysis}

We used Structure v.2.2 (Falush et al., 2003) to assess the number of distinct genetic clusters (k) irrespective of the geographic origin of the samples. Simulations were run with a burn-in period of 50,000 followed by an additional 500,000 steps. The number of populations was set to $1-20$, and 20 replicates for each $\mathrm{k}$ were run under an admixture model with correlated gene frequencies. The probability of $\mathrm{k}$ populations was calculated based in $\mathrm{Dk}$, as described in Evanno et al. (2005), and on a visual inspection of the plot of the $\ln P(D)$ as a function of $k$. Once $k$ was estimated, two replicates of a longer run with a 300,000 steps of burn-in following with a 1,000,000 steps were performed to assign individuals to clusters.

We also assessed genetic clusters using genetic and geographic information with the software GENELAND (Guillot et al., 2005) that tries to identify genetic spatial discontinuities introducing geographic information as Bayesian priors. Clusters corresponding to spatially organized groups are considered more likely than spatially random patterns. We conducted multiple preliminary runs to adjust input parameters, based on the behaviour of the MCMC, on the parameter space and on the convergence between chains. We first performed eight simulations of 1,000,000 MCMC iterations with a total of 58 runs, each with the selected set of parameters and the number of genetic groups $(\mathrm{k})$ as variable. Then, six simulations of 5,000,000 MCMC iterations with a total of 56 runs with variable $\mathrm{k}$, correlated frequencies and a maximum error of $200 \mathrm{~m}$ in the spatial coordinates due to the strong territorial behaviour and site fidelity of the species (Laiolo et al., 2007; Vögeli et al., 2008). We choose $\mathrm{k}$ as the most often selected across all simulations, considering in each simulation the one selected in the run with the best posterior density. Finally, we ran one simulation of 10 runs of $10,000,000$ MCMC with the $\mathrm{k}$ selected in the previous runs to assign individuals to clusters.

\subsubsection{Genetic differentiation}

Pairwise population genetic differentiation was estimated through an $\mathrm{F}_{\mathrm{ST}}$ matrix (Weir and Cockerham, 1984) using Genetix with 5000 permutations, and through other recently proposed differentiation indices: $G_{S T}^{0}$ (Hedrick, 2005) and $D_{\text {ST }}$ (Jost, 2008), using SMOGD version 1.2.5 (Crawford, 2010) with 999 bootstrap iterations. These two latter estimators are more robust to the bias introduced by differences in diversity among populations and more appropriate for highly polymorphic markers (Hedrick, 2005; Jost, 2008). For a better visualization of the results, neighbour joining trees were calculated using MEGA (Tamura et al., 2007).

\subsubsection{Spatial patterns}

We used two approaches to investigate how the spatial distribution of steppe patches and/or individuals can influence population differentiation patterns. First, we tested for IBD by performing a Mantel test of pairwise $F_{S T}, G_{S T}^{0}$, and $D_{S T}$ population's matrix on the log-transformed geographic distance matrix, using GeneAlEx with 9999 permutations (Peakall and Smouse, 2001). We expected, under stepping-stone framework and migration-drift equilibrium, a positive linear relationship which slope is representative of the degree of gene flow between populations (Koizumi et al., 2006). Geographic distances were calculated as the straight line connecting the geographic centre of the sampled patch. We plotted the three differentiation indexes $\left(F_{S T}, G_{S T}^{0}\right.$ and $\left.D_{S T}\right)$ with two input datasets. The first data set included all populations while the second one only included populations with more than six sampled individuals in order to ensure the robustness of the analyses despite the small sample size in some populations. Sample sizes were unavoidably constrained by the small size of many of the remaining populations; however, sample size correlated well with population size and small populations were exhaustively sampled (see Vögeli et al., 2011b). Second, we investigated spatial autocorrelation (SA) in genetic structure within the steppe patches at the individual level, using GenAlEx and following methods proposed by Smouse and Peakall (1999). This analysis allows us to determine whether related individuals are correlated in space, what might suggest that dispersal is limited by distance, even within patches. We used a pairwise geographical distance between individuals calculated as the linear distance separating them based on their XY capture coordinates. The average genetic similarity between pairs of individuals in a specific distance class is obtained by the autocorrelation coefficient (r) with 9999 permutations. This test only considers individuals within the same patch and we restricted the analysis to populations $(\mathrm{N}=9)$ with enough individuals to cover all the distance classes (Table 1 ).

\subsubsection{Mutation-drift, migration-drift equilibrium}

To assess the possibility of populations departing from genetic equilibrium as a consequence of recent reductions in gene flow or effective population sizes, we used two different approaches. First, we tested the mutation-drift equilibrium, using BOTTLENECK 1.2.02 (Cornuet and Luikart, 1996) which tests whether the number of loci with heterozygosis excess is significantly higher than that expected by chance at mutation-drift equilibrium. In populations that have experienced a recent reduction in effective size, the number of alleles is reduced faster than gene diversity, leading to a transient excess of heterozygosis (Luikart et al., 1998). We used two different models of microsatellite evolution: the strict stepwise mutation model (SMM) and the two-phase model (TPM), in which $30 \%$ of the mutations consisted of changes by more than a single repeat unit. Other combinations of the SMM:IAM ratio were tested to assess the robustness of the results. Probability values of heterozygosis excess or deficit were estimated by comparison with a null distribution based on 10,000 iterations using the Wilcoxon signed-rank test. Second, we tested whether the observed structure better fits a gene flow-drift equilibrium model or a pure drift model using coalescent-based MCMC simulations implemented in 2MOD (Ciofi et al., 1999). The first model assumes a balance between gene flow and drift while the second model assumes that the ancestral panmictic population is evolving into several different units diverging by drift in the absence of gene flow. We estimated the posterior distribution of F (probability of coancestry of any two genes in the putative population) for each population. Simulations were run with 600,000 steps with a burn-in of 100,000 in three independent runs. We used Tracer v 1.40 (http://beast.bio.ed.ac.uk/) to evaluate the stationarity of model parameters, verify adequate samples sizes, determine an 
Table 1

Attributes of the populations sampled. Reg = eco-geographic region to which the population belongs $(\mathrm{EV}=$ Ebro Valley, $\mathrm{SS}=$ Southern Spain, NP = Northern Plateau, $\mathrm{SP}=$ Southern $\quad$ Plateau, $\mathrm{IM}=$ Iberian Mountains, $\mathrm{M}=$ Morocco) $. \quad \mathrm{N}=$ sample size, $\mathrm{AR}=$ Allelic richness, $\mathrm{H}_{\mathrm{e}}=$ Expected heterozygosity, $\mathrm{H}_{\mathrm{o}}=$ observed heterozygosity, $\mathrm{F}_{\text {is }}=$ inbreeding coefficient, $\mathrm{HW}=$ Hardy-Weinberg equilibrium after Bonferroni correction, $\mathrm{F}=$ Differentiation index under a drift model. Statistically significant values are marked in bold.

\begin{tabular}{|c|c|c|c|c|c|c|c|c|}
\hline Population & Reg. & $\mathrm{N}$ & $\mathrm{AR}$ & $\mathrm{H}_{\mathrm{e}}$ & $\mathrm{H}_{\mathrm{o}}$ & $\mathrm{F}_{\text {is }}$ & $\mathrm{HW}$ & F \\
\hline Albalate & EV & 51 & 2.488 & 0.617 & 0.565 & 0.096 & 0.000 & 0.044 \\
\hline Alcaniz & EV & 11 & 2.376 & 0.557 & 0.497 & 0.165 & 0.343 & 0.077 \\
\hline Azaila & EV & 10 & 2.487 & 0.590 & 0.564 & 0.110 & 0.031 & 0.046 \\
\hline Ballobar & EV & 15 & 2.490 & 0.592 & 0.572 & 0.073 & 0.276 & 0.033 \\
\hline Bardenas & EV & 12 & 2.502 & 0.600 & 0.567 & 0.107 & 0.406 & 0.086 \\
\hline Belchite & EV & 61 & 2.561 & 0.638 & 0.598 & 0.072 & 0.000 & 0.026 \\
\hline Blancas & IM & 13 & 2.455 & 0.588 & 0.529 & 0.143 & 0.013 & 0.043 \\
\hline Cieza & SS & 22 & 2.511 & 0.609 & 0.587 & 0.060 & 0.118 & 0.042 \\
\hline Duraton & NP & 15 & 2.392 & 0.557 & 0.508 & 0.130 & 0.002 & 0.054 \\
\hline Gador & SS & 2 & 1.929 & 0.339 & 0.500 & -0.167 & 0.995 & 0.178 \\
\hline Gata & SS & 2 & 2.500 & 0.500 & 0.607 & 0.128 & 0.967 & 0.092 \\
\hline Grego & EV & 28 & 2.469 & 0.605 & 0.592 & 0.041 & 0.947 & 0.057 \\
\hline Laina & IM & 16 & 2.365 & 0.553 & 0.535 & 0.080 & 0.740 & 0.021 \\
\hline Lecera & EV & 11 & 2.467 & 0.595 & 0.656 & -0.052 & 0.218 & 0.077 \\
\hline Mediana & EV & 60 & 2.511 & 0.621 & 0.574 & 0.085 & 0.000 & 0.026 \\
\hline Moral & NP & 9 & 2.419 & 0.564 & 0.539 & 0.107 & 0.157 & 0.042 \\
\hline Moya & SP & 12 & 2.439 & 0.570 & 0.634 & -0.050 & 0.925 & 0.066 \\
\hline Padul & SS & 3 & 2.391 & 0.500 & 0.452 & 0.290 & 0.852 & 0.179 \\
\hline Penadil & EV & 10 & 2.396 & 0.563 & 0.611 & -0.030 & 0.849 & 0.044 \\
\hline PinaN & EV & 26 & 2.482 & 0.607 & 0.565 & 0.091 & 0.037 & 0.043 \\
\hline PinaS & EV & 26 & 2.541 & 0.630 & 0.632 & 0.020 & 0.359 & 0.041 \\
\hline Puebla & EV & 7 & 2.462 & 0.563 & 0.534 & 0.132 & 0.013 & 0.048 \\
\hline Rekkam & M & 9 & 2.556 & 0.605 & 0.618 & 0.042 & 0.709 & - \\
\hline Retortil & $\mathrm{IM}$ & 10 & 2.441 & 0.570 & 0.510 & 0.203 & 0.041 & 0.031 \\
\hline Saelices & SP & 5 & 2.651 & 0.594 & 0.644 & 0.052 & 0.993 & 0.012 \\
\hline Samper & EV & 9 & 2.418 & 0.568 & 0.587 & 0.028 & 0.921 & 0.029 \\
\hline Tariego & NP & 2 & 2.071 & 0.384 & 0.536 & -0.071 & 0.975 & 0.116 \\
\hline Tella & $\mathrm{EV}$ & 4 & 2.674 & 0.619 & 0.643 & 0.107 & 0.735 & 0.046 \\
\hline Torrero & EV & 3 & 2.386 & 0.497 & 0.560 & 0.096 & 0.921 & 0.137 \\
\hline Urrea & EV & 10 & 2.491 & 0.602 & 0.585 & 0.086 & 0.735 & 0.082 \\
\hline Valeria & SP & 16 & 2.437 & 0.588 & 0.621 & -0.021 & 0.124 & 0.046 \\
\hline Visiedo & IM & 11 & 2.485 & 0.587 & 0.612 & 0.013 & 0.994 & 0.040 \\
\hline Zafra & SP & 8 & 2.601 & 0.612 & 0.602 & 0.093 & 0.314 & 0.031 \\
\hline Zamora & NP & 6 & 2.353 & 0.535 & 0.586 & 0.004 & 0.951 & 0.115 \\
\hline Zeida & M & 22 & 2.623 & 0.646 & 0.582 & 0.129 & 0.089 & - \\
\hline
\end{tabular}

appropriate amount of burn-in, and verify the consistency between runs.

\section{Results}

\subsection{Genetic diversity}

A total of 537 individuals from 35 populations (33 from Spain and two from Morocco) were genotyped for 14 microsatellites. Following Bonferroni correction, only two out of the 3281 tests for LD were statistically significant (p-values $>0.05$ ); those tests involved different loci comparisons and occurred in different breeding aggregations, suggesting that the assayed loci likely evolved independently. The genetic diversity results are present in Table 1 . Three populations (Albalate, Belchite and Mediana) showed significant HW disequilibrium after Bonferroni correction. Among Spanish populations, $\mathrm{H}_{\mathrm{e}}$ ranged from 0.339 to 0.638 , being highest in one of the larger populations (Belchite) and lowest in one of the smaller and more isolated (Gador). Moroccan populations showed high heterozygosities values being Zeida the most diverse $\left(\mathrm{H}_{\mathrm{e}}=0.646\right)$. The number of observed alleles was variable, ranging from 1.929 in Gador to 7.571 in Mediana, with an overall average of 4.718. AR, standardized to a sample size of $\mathrm{N}=2$, showed a narrower range, from 1.929 in Gador to 2.561 in Saelices, with an average of 2.452. Nineteen populations showed a homozygote excess, as reflected in high and significant $\mathrm{F}_{\text {is }}$ values.

\subsection{Bayesian clustering analysis}

We obtained different results from Geneland and Structure analyses. Structure detected two genetic clusters (Morocco and Spain), whereas Geneland inferred 13, two in Morocco (one for each sampled population) and 11 in Spain. In the 56 runs performed to estimate $\mathrm{k}$ with Geneland, the posterior density and the log-likelihood levels reached a plateau before the end of the MCMC runs, indicating that they had reached convergence. These replicate runs gave generally consistent results: in 44 of the 56 runs, the modal number of genetic groups $(k)$ was 13 ; in the remaining runs they were $12(\mathrm{~N}=5)$ and $14(\mathrm{~N}=7)$. Therefore, final simulation with 10 runs was performed with $\mathrm{k}$ set to 13 . Two clusters match the two Moroccan populations, and 11 correspond to Spanish populations (see Fig. 1 for cluster distribution). In Spain, five clusters were unique for the five previously described ecogeographical regions. Clusters 1,2 and 4 were found in EV, cluster 10 in NP and 13 in SS. However, six clusters were shared between regions even in the presence of likely historical barriers to gene flow, or differences in topography and steppe availability. For example, cluster 3 is present in EV and IM, 5 in NP and IM, 7 in SS and SP, 9 in SS, NP, EV and IM, 11 in NP and SP, and 12 in NP and IM.

\subsection{Genetic structure}

A statistically significant but moderate overall genetic differentiation was obtained for the dataset including all populations (global $\mathrm{F}_{\mathrm{ST}}=0.023,95 \% \mathrm{CI}=0.018-0.027$ ). Differentiation remained significant when only Spanish populations were considered (global $\left.\mathrm{F}_{\mathrm{ST}}=0.020,95 \% \mathrm{CI}=0.016-0.025\right)$, rejecting the hypothesis of a single panmictic population. The overall genetic differentiation was higher based on alternative measures such as $\mathrm{D}_{\mathrm{ST}}(0.056)$, and was significant in 53\% of the pairwise comparisons, with estimated $\mathrm{F}_{\mathrm{ST}}$ values ranging from -0.032 to 0.206 (see Appendix A for differentiation matrices of $\mathrm{F}_{\mathrm{ST}}, \mathrm{G}_{\mathrm{ST}}^{0}$ and $\mathrm{D}_{\mathrm{ST}}$, and their corresponding neighbour-joining trees). All differentiation indexes $\left(F_{\mathrm{ST}}, \mathrm{G}_{\mathrm{ST}}^{0}, \mathrm{D}_{\mathrm{ST}}\right)$ where highest in comparisons involving Gador, Padul, Torrero and Zamora populations. Those are among the smallest and most isolated populations, belonging to SS and NP regions.

\subsection{Spatial patterns}

IBD analyses showed a positive overall relationship between genetic and geographic distances (Fig. 2a). Nevertheless, correlation coefficients were low $\left(r=0.15,0.16\right.$ and 0.09 for $D_{S T}, G_{S T}^{0}$ and $F_{S T}$ respectively) and even lower when analyses were restricted to populations with more than six individuals (Fig. 2b). These results are consistent across the three differentiation measures, although the variance explained by distance was higher for the alternative indices $\left(D_{\mathrm{ST}}, \mathrm{G}_{\mathrm{ST}}^{0}\right)$ than for traditional $\mathrm{F}_{\mathrm{ST}}$.

The within-population analysis indicated the occurrence of spatial genetic autocorrelation at the first distance classes (500, 1000 and $1500 \mathrm{~m}$ ) in six out of the nine populations (Appendix B). In two populations, $r$ declines at larger distance classes, becoming significantly negative beyond $2000 \mathrm{~m}$.

\subsection{Mutation-drift and migration-drift equilibrium}

We detected some differences between TPM and SMM models in our bottleneck analyses. The overall evidence for recent demographic bottlenecks was weak (Appendix C). Heterozygote excess, indicative of recent declines, was only detected under a TPM model in two populations from EV (PinaS and Lécera), whereas Mediana showed a signal of population expansion under SMM.

The coalescent model assuming a mechanism of drift in isolation was consistently selected against a model that assumed equi- 
a) Spain
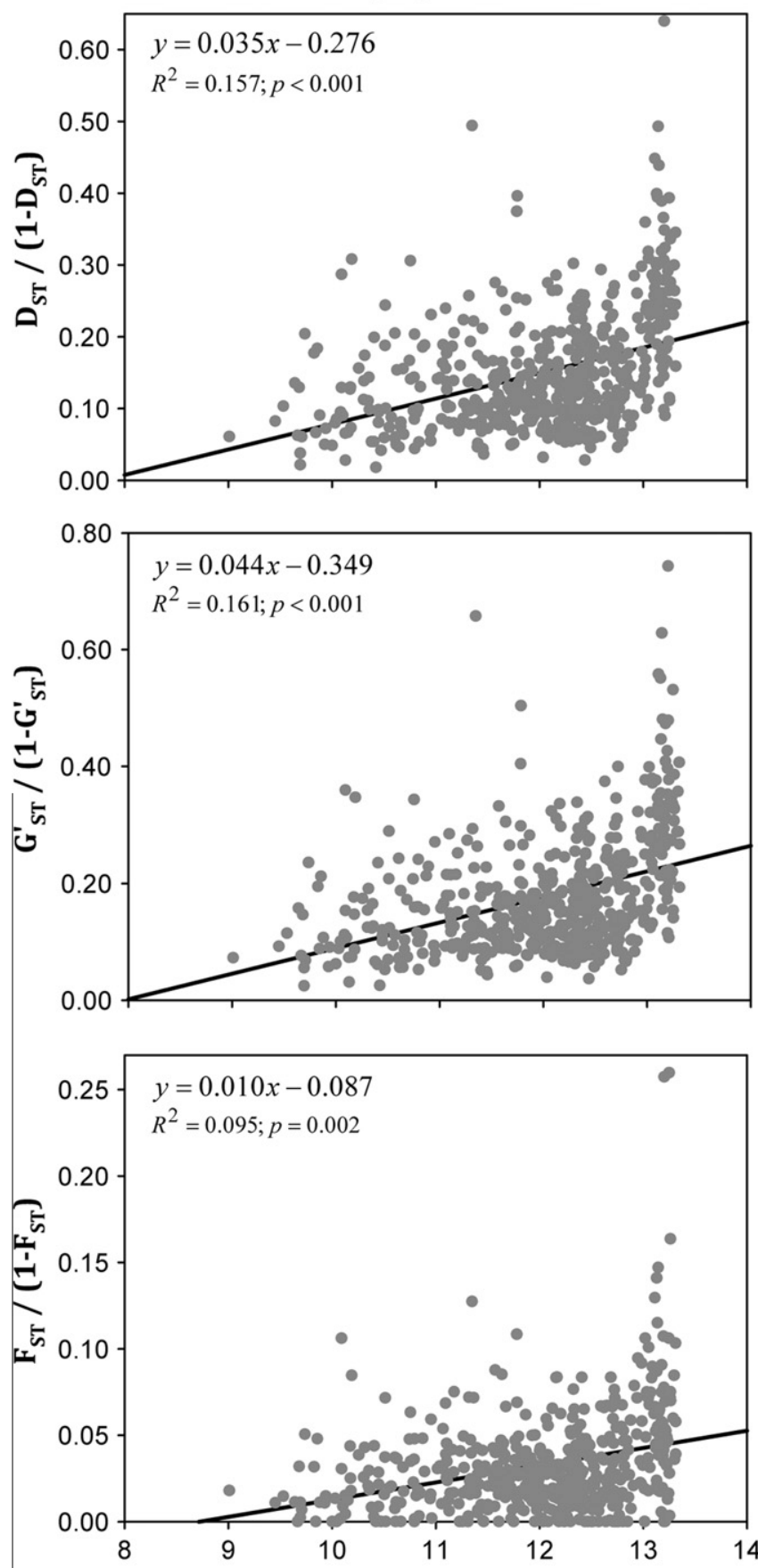

b) Spain $(n \geq 6)$
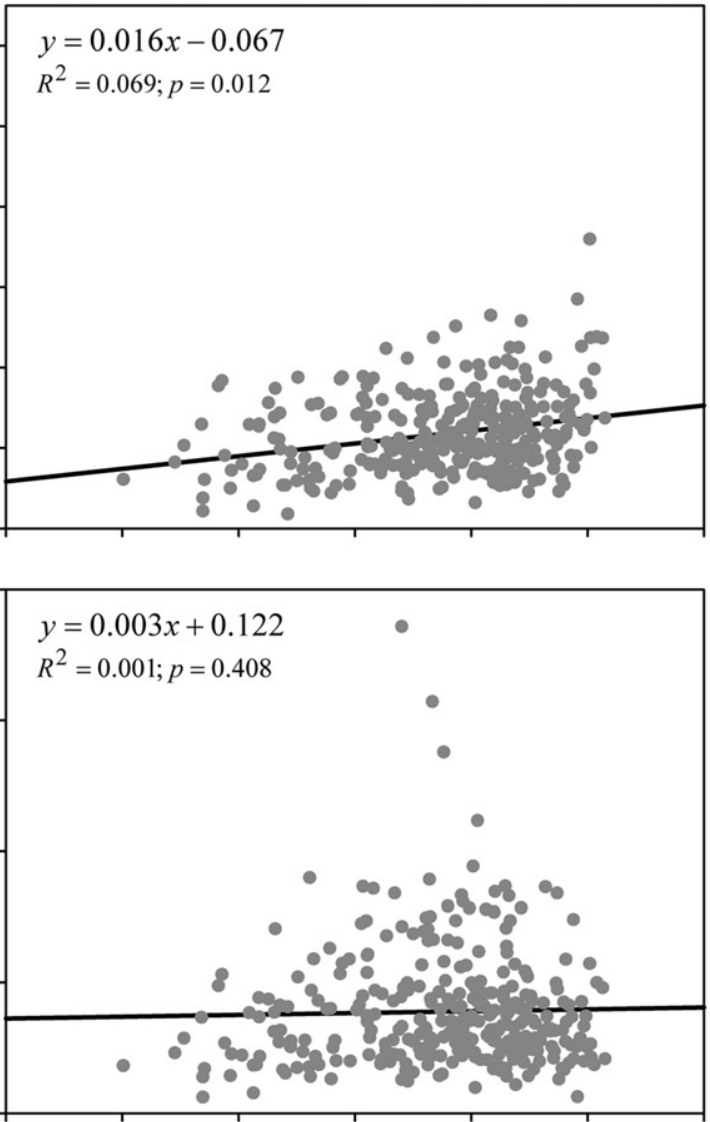

$y=0.006 x-0.045$

$R^{2}=0.081 ; p=0.009$

$\log$ (Geographic distance) (m)


as $D_{\mathrm{ST}}, \mathrm{G}_{\mathrm{ST}}^{0}$ or $\mathrm{F}_{\mathrm{ST}}$ on the y-axis. (a) all populations. (b) populations with six or more genotyped individuals.

librium between drift and gene flow (posterior probability =1), indicating that drift is the main factor influencing genetic patterns. There was, however, considerable variation in the extent of allele coancestry estimated under the drift model for the different populations $(0.012<\mathrm{F}<0.179$; Table 1$)$, which was, however, concordant with pairwise genetic distances calculated by traditional $\mathrm{F}_{\mathrm{ST}}$ in indicating that genetic drift was more intense in the smallest and more isolated populations, like Padul, Gador, Torrero, Zamora and Gata.

\section{Discussion}

\subsection{Differences in genetic patterns between continents}

Our results show that the remaining European populations of Dupont's lark (restricted to Spain) differ genetically in diversity and structure from the closest North African ones. We found a higher genetic diversity in Morocco, where one of the two sampled populations (Zeida) showed the highest diversity while the other 
(Rekkam) was as diverse as the most diverse Spanish populations. Besides, Moroccan and Spanish populations are clearly separated in two distinct genetic clusters. These results support the hypothesis that the Mediterranean Sea acts as a major barrier against gene flow for this species (García et al., 2008).

\subsection{Macrogeographic genetic patterns in Spain}

Habitat modelling identified five ecogeographic regions where extant Spanish populations of Dupont's lark populations are grouped (Laiolo and Tella, 2006b). These regions differ in topography, degree of steppe fragmentation, habitat availability and demographic histories in the last decades, and are delimited by likely barriers to gene flow (Laiolo and Tella, 2006b). Geneland analyses partially supported this macrogeographic picture, since five clusters were unique for the five previously described regions. However, all regions included more than one genetic cluster and six clusters were shared between regions. These results change the current view of "geographic units" for the conservation of this species, suggesting a larger historical gene flow among regions than previously thought.

Our analyses support a model of isolation by distance, as it is the case of other steppe bird with limited dispersal (Alcaide et al., 2009a,b), although the relationship between genetic and geographic distances is weak. Call dissimilarities of Dupont's larks also follow a clear pattern of isolation by distance, with landscape configuration forcing individual movements through pathways of suitable habitats and thus constraining the circulation of call types (Laiolo and Tella, 2006b). These observations might be interpreted as an evidence of an ancestral genetic dynamics that included substantial effective gene flow between regions, which contrasts with the limited dispersal indicated by contemporary capture-mark-recapture data. Although these latter analyses might miss important low frequency but genetically relevant long-distance dispersal events (Alcaide et al., 2009b), overall evidence seems to indicate that the isolation of the populations is quite recent.

\subsection{Multi-scale effects of habitat loss and fragmentation}

In addition to a historical signal of gene flow and panmixia among regions, we also found genetic signals of a population decline probably caused by recent habitat fragmentation. The transformation of steppes in the last few decades caused not only the net loss of habitat (Laiolo and Tella, 2006a), which may affect directly population sizes, but also the loss of whole steppe patches that could be acting as corridors for dispersal movements among regions (Laiolo and Tella, 2006b; Tella et al., 2005; Méndez et al., unpublished) with the consequent reduction of gene flow. As many studies have shown, fragmentation, by decreasing population size and increasing isolation between patches, may intensify drift and cause a decrease in diversity and an increase in structure and inbreeding (Frankham et al., 2002). Our results indicate that Dupont's lark populations are already showing the effects of recent drift on genetic diversity, inbreeding and structure. Firstly, a pure drift model was overwhelmingly supported over a mutation-drift equilibrium model. Furthermore, allele coancestry estimated under this model was highest for some of the smallest and most isolated populations. Secondly, both moment-based and model-based analyses of population structure revealed a pattern of high differentiation with little geographic correlation. Nearby populations often showed high differentiation indices, whereas the most genetically related populations are sometimes geographically distant. Finally, some populations show much reduced genetic diversity with respect to Moroccan and other Spanish populations. The lowest levels of genetic diversity usually corresponded to the smallest populations in regions where habitat availability and con- nectivity is scarce, such as the Northern Plateau and Southern Spain, while the higher levels corresponded to populations mainly from the Ebro Valley, a region with small fragments but still partially connected (Laiolo and Tella, 2006b). All these results together indicate that Spanish Dupont's lark populations are already showing the genetic consequences of a recent fragmentation.

Differentiation is often apparent not only between populations, but also within populations and even between individuals inhabiting the same habitat patch. Attending to spatial autocorrelation analyses, the first distance classes seem to hold genetically related individuals, in agreement with previous bioacoustics spatial analyses showing that the first $1500 \mathrm{~m}$ hold individuals with similar song types (Laiolo and Tella, 2005). Vocalizations may be important to understand isolation, due to their role in mate choice and sexual selection and rapid cultural changes (Grant and Grant, 1996; Laiolo, 2010), to the point that cultural divergence might eventually act as a barrier to gene flow (i.e. Attard et al., 2010; Badyaev et al., 2008; MacDougall-Shackleton and MacDougallShackleton, 2001) with potentially serious implications for population structure and genetic diversity. Nonetheless, vocalizations are culturally transmitted and thus they can evolve irrespective of individual relatedness (Laiolo and Tella, 2007). The strong correspondence we have found between vocal and genetic patterns, however, suggests that the former may also reflect genetic processes occurring within local populations. This small-scale spatial genetic and cultural autocorrelation can explain the observed high levels of inbreeding found in many Dupont's lark populations. It also suggests that movement of individuals are restricted not only among populations, but also within populations without apparent landscape barriers, indicating a very limited dispersal capacity in agreement with previous conclusions derived from field studies (Laiolo et al., 2007; Vögeli et al., 2010).

\subsection{Bottlenecks and crowding effects}

Fragmentation effects can be delayed in some species by large population sizes or long generation times, so that genetic patterns may still reflect the ancestral panmictic situation. This is an important issue in conservation, because we can diagnose a favourable status for populations that are actually demographically compromised and isolated. Bottleneck tests may be particularly prone to this situation due to their often limited and not fully evaluated statistical power. Although these tests were statistically significant only for two populations, we expect many more to have suffered recent bottlenecks and some are predicted to become extinct in the near future by their negative population growth rates (Laiolo et al., 2008; Vögeli et al., 2011a,b). This fact may be explained by different limitations when testing demographic bottlenecks. First, current statistical tests only have power to detect very severe and extended reductions in population size (Cornuet and Luikart, 1996) and they heavily depend on the mutation model used, the repeat motif of the microsatellites or the number and variability of markers (Cristescu et al., 2010). Second, the characteristics of the bottlenecks may also play a role, such as the time since they occurred, their depth and duration (Spencer et al., 2000; Busch et al., 2007). Third, there may be species-specific constraints. Several studies have shown that large generation times can act as a buffer for genetic diversity, making the early detection of bottlenecks difficult (e.g. Hailer et al., 2006). However, this is not the case for the short-lived Dupont's lark, whose generation time is estimated in 2 years (García et al., 2008). We propose that population crowding could be another species-specific limitation. Previous studies have shown that Dupont's lark breeding densities increased as the steppe patch size decreased, suggesting crowding effects both at national (Laiolo and Tella, 2006a) and regional scales (Vögeli et al., 2010). As habitat is being fragmented and reduced, birds 
may be forced to occupy the entire remaining habitat rather than disperse to another steppe patch. Therefore, local populations tend to crowd and increase in density, consequently retarding local population size reductions. In such situations, some genetic effects such as increased differentiation, decreased diversity and bottleneck signals may be delayed, while inbreeding and relatedness may increase, thus becoming better indicators of the fragmentation. In fact, several Dupont's lark local populations went extinct in very recent years (Tella et al., 2005; Laiolo et al., 2008), and the only one we could characterise genetically before its extinction (Alcañiz) showed high levels of inbreeding and relatedness. Therefore, the significant levels of inbreeding, the high relatedness within patches and the increased spatial genetic structure, even within steppe patches, that we observed in most of the extant Spanish Dupont's lark populations raise serious concerns on their short-term viability.

\subsection{Conclusions and conservation implications}

All our results are in concordance with previous ecological (Laiolo and Tella, 2006a; Vögeli et al., 2010), behavioural (Laiolo and Tella, 2005, 2006b, 2007), demographic (Laiolo et al., 2007, 2008; Vögeli et al., 2008, 2011a), and epidemiological studies (Vögeli et al., 2011b), supporting that recent habitat fragmentation is isolating and threatening the remnant Dupont's lark populations at different spatial scales. However, the effects of fragmentation are not reflected in the same way in ecological dynamics or in genetics. Crowding effects or other phenomena that retard genetic effects may produce a bimodal pattern, with populations where the effects of drift are more evident and populations that apparently still reflect a pre-fragmentation pattern. Habitat loss and fragmentation for this type of species may lead to extinction before genetics is heavily impacted. In our case, local patterns of increased genetic structure or inbreeding may be signalling a rapid decline of the populations.

Several conservation implications are derived from our genetic screening of Dupont's lark populations. First, the separate evolutionary history of North-African and European populations and absence of gene flow has resulted in phenotypic differentiation and reciprocal monophyly for mitochondrial haplotypes (García et al., 2008) and high level of differentiation in nuclear allelic frequencies (this study), what supports the delimitation of Spanish and Moroccan populations as two evolutionary significant units (Moritz, 1994) requiring separate conservation plans. Second, Spanish conservation actions should not focus separately on the five ecogeographical regions previously considered, since they are composed by local populations forming different genetic clusters, several of them shared by different regions. Each cluster should be considered as a management unit for conservation due to the combination of low dispersal of the species and high isolation of habitat patches. Third, steppe patches currently occupied by the species should be protected and its size increased, by regenerating steppe vegetation in surrounding agricultural lands. Fourth, steppe habitat corridors and/or patches that could function as stepping-stones should be urgently created between populations to increase their connectivity and restore gene flow. Since the Dupont's lark seems to be a very good indicator of the amount of transformation that steppes can support before their biodiversity is severely affected (Laiolo and Tella, 2006a), these habitat-focused management actions would also benefit to a rich community of threatened steppe birds.

Habitat regeneration has been already proposed as the most evident and urgent measure to increase the size and connectivity of the remaining steppe patches inhabited by Dupont's larks (Vögeli et al., 2010). This action, however, may be too slow to reverse in time the current way towards extinction of this species.
Large extensions of low-productive agricultural lands should be acquired to regenerate natural steppes, and regeneration may need the implementation of techniques whose evaluation of effectiveness may require decades of work (see Pywell et al., 2011 for the case of grassland regeneration). Facing this likely slow management process, translocation of individuals could be considered as a complementary and faster way to attenuate the genetic effects of population fragmentation and the extinction risk of small populations. Moreover, in the case of species in which social learning and culture are important determinants of behaviour, translocations should help to protect both genetic and cultural diversity (Whithehead, 2010). Translocations must, however, be designed with extreme care since they may cause undesirable effects, as individuals adapted to local environments may be less fit in novel habitats, and the introduction of their alleles could dilute local adaptation in the recipient population (Storfer, 1999; Johnson, 2000; Edmands, 2007). Fortunately, there is already available abundant information on local eco-morphological adaptations (Vögeli, 2009), exposure to pathogens (Vögeli et al., 2011b) and culture diversity (Laiolo and Tella, 2007) that, combined with this genetic work, would allow translocations of Dupont's larks without compromising current local adaptations and cultural diversity.

\section{Acknowledgements}

We thank M. Vögeli, D. Serrano, I. Afán and P. Laiolo for helping with sample collection, and A. Píriz, L. Soriano and A. Centeno for guidance in the laboratory work. M. Vögeli provided helpful comments and maps. The comments by two anonymous reviewers helped to improve the contents of the manuscript. Funding was provided by Excellence Project RNM1274 (Junta de Andalucía) and a PhD fellowship of Telefónica Móviles S.A. enjoyed by $\mathrm{M}$. Méndez.

\section{Supplementary material}

Supplementary data associated with this article can be found, in the online version, at doi:10.1016/j.biocon.2011.07.011.

\section{References}

Alcaide, M., Serrano, D., Negro, J.J., Tella, J.L., Laaksonen, T., Müller, C., Gal, A. Korpimäki, E., 2009a. Population fragmentation leads to isolation by distance but not genetic impoverishment in the phylopatric Lesser Kestrel: a comparison with the widespread and sympatric Eurasian Kestrel. Heredity 102, 190-198.

Alcaide, M., Serrano, D., Tella, J.L., Negro, J.J., 2009b. Strong philopatry derived from capture-recapture methods does not lead to fine-scale genetic differentiation in lesser kestrels. Journal of Animal Ecology 78, 468-475.

Attard, M.R.G., Pitcher, B.J., Charrier, I., Ahonen, H., Harcourt, R.G., 2010. Vocal discrimination in mate guarding male Australian sea lions: familiarity breeds contempt. Ethology 116, 704-712.

Badyaev, A.V., Young, R.L., Oh, K.P., Addison, C., 2008. Evolution on a local scale: developmental, functional, and genetic bases of divergence in bill form and associated changes in song structure between adjacent habitats. Evolution 62, 1951-1964.

Belkhir, K., Borsa, P., Chikhi, L., Raufaste, N., Bonhomme, F., 1996-2004. GENETIX 4.05, logiciel sous Windows TM pour la génétique des populations. Laboratoire Génome, Populations, Interactions, CNRS UMR 5000, Université de Montpellier II, Montpellier, France.

BirdLife International, 2008. Chersophilus duponti. 2008 IUCN Red List of Threatened Species. <http://www.iucnredlist.org>.

Burfield, I., van Bommel, F., 2004. Birds in Europe: Populations Estimates, Trends and Conservation Status. BirdLife International, Cambridge.

Busch, J.D., Waser, P.M., DeWoody, J.A., 2007. Recent demographic bottlenecks are not accompanied by a genetic signature in banner-tailed kangaroo rats (Dipodomys spectabilis). Molecular Ecology 16, 2450-2462.

Ciofi, C., Beaumont, M.A., Swingland, I.R., Bruford, M.W., 1999. Genetic divergence and units for conservation in the Komodo dragon Varanus komodoensis. Proceedings of the Royal Society B: Biological Sciences 266, 2269-2274.

Cornuet, J.M., Luikart, G., 1996. Description and power analysis of two tests for detecting recent population bottlenecks from allele frequency data. Genetics 144, 2001-2014 
Cramp, S., 1988. The Birds of the Western Palaearctic, vol. 5. Oxford University Press, Oxford, UK.

Crawford, N.G., 2010. SMOGD: software for the measurement of genetic diversity. Molecular Ecology Resources 10, 556-557.

Cristescu, R., Sherwin, W.B., Handasyde, K., Cahill, V., Cooper, D.W., 2010. Detecting bottlenecks using BOTTLENECK 1.2.02 in wild populations: the importance of the microsatellite structure. Conservation Genetics 11, 1043-1049.

Davies, K.F., Margules, C.R., Lawrence, J.F., 2004. A synergistic effect puts rare, specialized species at greater risk of extinction. Ecology 85, 265-271.

Edmands, S., 2007. Between a rock and a hard place: evaluating the relative risks of inbreeding and outbreeding for conservation and management. Molecular Ecology 16, 463-475.

Evanno, G., Regnaut, S., Goudet, J., 2005. Detecting the number of clusters of individuals using the software STRUCTURE: a simulation study. Molecular Ecology 14, 2611-2620.

Falush, D., Stephens, M., Pritchard, J.K., 2003. Inference of population structure using multilocus genotype data: linked loci and correlated allele frequencies. Genetics 164, 1567-1587.

Frankham, R., Ballou, J., Briscoe, D., 2002. Introduction to Conservation Genetics. Cambridge University Press, New York.

Frankham, R., 2005. Genetics and extinction. Biological Conservation 126, 131-140.

García, J.T., Suárez, F., Garza, V., Calero-Riestra, M., Hernández, J., Pérez-Tris, J., 2008. Genetic and phenotypic variation among geographically isolated populations of the globally threatened Dupont's lark Chersophilus duponti. Molecular Phylogenetics and Evolution 46, 237-251.

Garza, V., Suárez, F., Tella, J.L., 2004. Alondra de Dupont, Chersophilus duponti. In: Madroño, A., González, F., Atienza, J.C. (Eds.), Libro Rojo de las Aves de España. Dirección General para la Biodiversidad-SEO/Birdlife, Madrid, pp. 309-312.

Garza, V., Suárez, F., Herranz, J., Traba, J., De La Morena, E.G., Morales, M.B., González, R., Castañeda, M., 2005. Space use and habitat selection of the endangered Dupont's lark in Spain: the breeding and postbreeding periods. Ardeola 52, 133-146.

Gemmell, N.J., Akiyama, S., 1996. An efficient method for the extraction of DNA from vertebrate tissues. Trends in Genetics 12, 338-339.

Gerlach, G., Musolf, K., 2000. Fragmentation of landscape as a cause for genetic subdivision in bank voles. Conservation Biology 14, 1066-1074.

Goudet, J., 2001. FSTAT, A Program to Estimate and Test Gene Diversities and Fixation Indices (Version 2.9.3). <http://www.unil.ch/izea/softwares/ fstat.html > (Updated From Goudet (1995)).

Grant, B.R., Grant, P.R., 1996. Cultural inherence of song and its role in the evolution of Darwin finches. Evolution 50, 2471-2487.

Guillot, G., Mortier, F., Estoup, A., 2005. GENELAND: a program for landscape genetics. Molecular Ecology Notes 5, 712-7115.

Hailer, F., Helander, B., Folkestad, A.O., Ganusevich, S.A., Gastard, S., Hauff, P., Koren, C., Nygard, T., Volke, V., Vila, C., 2006. Bottlenecked but long-lived: high genetic diversity retained in white-tailed eagles upon recovery from population decline. Biology Letters 2, 316-319.

Hedrick, P.W., 2005. A standardized genetic differentiation measure. Evolution 59, 1633-1638.

Johnson, M.S., 2000. Measuring and interpreting genetic structure to minimize the genetic risks of translocations. Aquaculture 31, 133-143.

Jost, L., 2008. $\mathrm{G}_{\mathrm{ST}}^{0}$ and its relatives do not measure differentiation. Molecular Ecology 17, 4015-4026.

Koizumi, I., Yamamoto, S., Maekawa, K., 2006. Decomposed pairwise regression analysis of genetic and geographic distances reveals a metapopulation structure of stream-dwelling Dolly Varden charr. Molecular Ecology 15, 3175-3189.

Laiolo, P., 2010. The emerging significance of bioacoustics in animal species conservation. Biological Conservation 143, 1635-1645.

Laiolo, P., Tella, J.L., 2005. Habitat fragmentation affects culture transmission: patterns of song matching in Dupont's lark. Journal of Applied Ecology 42, 1183-1193.

Laiolo, P., Tella, J.L., 2006a. The fate of unproductive and anaesthetic habitats: recent changes in Iberian steppes and their avifauna. Environmental Conservation 33, 223-232.

Laiolo, P., Tella, J.L., 2006b. Landscape bioacoustics allows detection of the effects of habitat patchiness on population structure. Ecology 87, 1203-1214.

Laiolo, P., Tella, J.L., 2007. Erosion of animal cultures in fragmented landscapes. Frontiers in Ecology and the Environment 5, 68-72.

Laiolo, P., Tella, J.L., 2008. Demographic determinants of bird song activity, conspecific attraction, and implications for the persistence of small populations. Animal Conservation 11, 433-441.

Laiolo, P., Vögeli, M., Serrano, D., Tella, J.L., 2007. Testing acoustic versus physical marking: two complementary methods for individual-based monitoring of elusive species. Journal of Avian Biology 38, 672-681.

Laiolo, P., Vögeli, M., Serrano, D., Tella, J.L., 2008. Song diversity predicts the viability of fragmented bird populations. PLoS ONE 3, e1822.

Luikart, G., Allendorf, F.E., Cornuet, J.M., Sherwin, W.B., 1998. Distortion of allele frequency distributions provides a test for recent populations bottlenecks. Journal of Heredity 89, 238-247.
MacDougall-Shackleton, E.A., MacDougall-Shackleton, S.A., 2001. Cultural and genetic evolution in mountain white-crowned sparrows: song dialects are associated with population structure. Evolution 55, 2568-2575.

Méndez, M., Prats, L., Tella, J.L., Godoy, J.A., 2011. Isolation and characterization of twenty polymorphic microsatellite markers for the endangered Dupont's lark (Chersophilus duponti) and cross-amplification in crested lark (Galerida cristata) and thekla lark (Galerida theklae). Conservation Genetic Resources 3, 107-111.

Morin, P.A., Leduc, R.G., Archer, F.I., Martien, K.K., Huebinger, R., Bickham, J.W., Taylor, B.L., 2009. Significant deviations from Hardy-Weinberg equilibrium caused by low levels of microsatellite genotyping errors. Molecular Ecology Resources 9, 498-504.

Moritz, C., 1994. Defining evolutionarily-significant-units for conservation. Trends in Ecology and Evolution 9, 373-375.

Peakall, R., Smouse, P.E., 2001. GENALEX Version 5: Genetic Analysis in Excel, Population Genetics Software for Teaching and Research. Australian National University, Canberra. <http://www.anu.edu.au/BoZo/GenAlEx>.

Pywell, R.F., Meek, W.R., Webb, N.R., Putwain, P.D., Bullock, J.M., 2011. Long-term heathland restoration on former grassland: the results of a 17-year experiment. Biological Conservation. doi:10.1016/j.biocon.2011.02.010.

Raymond, M., Rousset, F., 1995. GENEPOP (version 1.2): population genetics software for exact tests and ecumenicism. Journal of Heredity 86, 248-249.

Richmond, J.Q., Reid, D.T., Ashton, K.G., Zamudio, K.R., 2009. Delayed genetic effects of habitat fragmentation on the ecologically specialized Florida sand skink (Plestiodon reynoldsi). Conservation Genetics 10, 1281-1297.

Rousset, F., 2008. Genepop'007: a complete reimplementation of the Genepop software for Windows and Linux. Molecular Ecology Resources 8, 103-106. Seoane, J., Justribo, J.H., Garcia, F., Retamar, J., Rabadan, C., Atienza, J.C., 2006. Habitat-suitability modelling to assess the effects of land-use changes on Dupont's lark Chersophilus duponti: a case study in the Layna Important Bird Area. Biological Conservation 128, 241-252.

Slatkin, M., 1993. Isolation by distance in equilibrium and non-equilibrium populations. Evolution 47, 264-279.

Smouse, P.E., Peakall, R., 1999. Spatial autocorrelation analysis of individual multiallele and multilocus genetic structure. Heredity 82, 561-573.

Schlotterer, C., 2004. The evolution of molecular markers - just a matter of fashion? Nature Reviews Genetics 5, 63-69.

Spencer, C.C., Neigel, J.E., Leberg, P.L., 2000. Experimental evaluation of the usefulness of microsatellite DNA for detecting demographic bottlenecks. Molecular Ecology 9, 1517-1528.

Storfer, A., 1999. Gene flow and endangered species translocations: a topic revisited. Biological Conservation 87, 173-180.

Suárez, F., García, J.T., Carriles, E., Calero-Riestra, M., Aguirre, A., Justribó, J.H., Garza, V., 2009. Sex-ratios of an endangered lark after controlling for a male-biased sampling. Ardeola 56, 113-118.

Sumner, J., Jessop, T., Paetkau, D., Moritz, C., 2004. Limited effect of anthropogenic habitat fragmentation on molecular diversity in a rain forest skink, Gnyetoscincus queenslandiae. Molecular Ecology 13, 259-269.

Tamura, K., Dudley, J., Nei, M., Kumar, S., 2007. MEGA4: molecular evolutionary genetics analysis (MEGA) software version 4.0. Molecular Biology and Evolution 24, 1596-1599.

Tella, J.L., Vögeli, M., Serrano, D., Carrete, M., 2005. Current status of the threatened Dupont's lark in Spain: overestimation, decline, and extinction of local populations. Oryx 39, 90-94.

Tucker, G., Heath, M.F., 1994. Birds in Europe: Their Conservation Status. BirdLife International, Cambridge.

Van Oosterhout, C., Hutchinson, W.F., Wills, D.P.M., Shipley, P., 2004. MICROCHECKER: software for identifying and correcting genotyping errors in microsatellite data. Molecular Ecology Notes 4, 535-538.

Vögeli, M., 2009. Ecology and Conservation Biology of the Dupont's Lark in Fragmented Landscapes. PhD Thesis, Universidad de Sevilla, Spain.

Vögeli, M., Laiolo, P., Serrano, D., Tella, J.L., 2008. Who are we sampling? Apparent survival differs between methods in a secretive species. Oikos 117, 1816-1823.

Vögeli, M., Serrano, D., Tella, J.L., Méndez, M., Godoy, J.A., 2007. Sex determination Dupont's lark Chersophilus duponti using molecular sexing and discriminant functions. Ardeola 54, 69-79.

Vögeli, M., Serrano, D., Pacios, F., Tella, J.L., 2010. The relative importance of patch habitat quality and landscape attributes on a declining steppe-bird metapopulation. Biological Conservation 143, 1057-1067.

Vögeli, Laiolo P., Serrano, D., Tella, J.L., 2011a. Predation of experimental nests is linked to local population dynamics in a fragmented bird population. Biology Letters. doi:10.1098/rsbl.2011.0241.

Vögeli, M., Lemus, J.A., Serrano, D., Blanco, G., Tella, J.L., 2011b. An island paradigm on the mainland: host population fragmentation impairs the community of avian pathogens. Proceedings of the Royal Society London Series B. doi:10.1098/ rspb.2010.1227.

Weir, B.S., Cockerham, C.C., 1984. Estimation F-statistics for the analysis of population structure. Evolution 38, 1358-1370.

Whithehead, H., 2010. Conserving and managing animals that learn socially and share cultures. Learning and Behaviour 38, 329-336. 